\title{
Outcome of ClosureFAST radiofrequency ablation for large-diameter incompetent great saphenous vein
}

\author{
Hye Young Woo ${ }^{1, *}$, Suh Min Kim²,*, Daehwan Kim¹, Jung Kee Chung ${ }^{1}$, In Mok Jung' \\ ${ }^{1}$ Department of Surgery, Seoul Metropolitan Government - Seoul National University Boramae Medical Center, Seoul, Korea \\ ${ }^{2}$ Department of Surgery, Dongguk University IIsan Hospital, Goyang, Korea
}

\begin{abstract}
Purpose: There is limited data on the outcomes of radiofrequency ablation (RFA) for large diameter saphenous veins. This study aimed to determine whether the large-diameter great saphenous vein (GSV) affected closure rate, complications, and clinical and quality of life (QoL) improvement.

Methods: From January 2012 to September 2016, a total of 722 limbs were treated with ClosureFAST RFA in a single center. Patients were divided into 2 groups according to the vein diameter measured $3 \mathrm{~cm}$ below the saphenofemoral junction (group $A \leq 12 \mathrm{~mm}$, group $B>12 \mathrm{~mm}$ ). Vein closure was evaluated with duplex scan at $3-5$ days, 1, 3, 6, and 12 months postoperatively. The incidence of complications, improvements in symptoms (measured by the Venous Clinical Severity Score [VCSS]) and QoL (measured by the Aberdeen Varicose Vein Symptom Severity Score [AVSS]) were evaluated. Results: Groups consisted of $663 \mathrm{GSV}$ in group A (mean diameter, $6.00 \pm 1.74 \mathrm{~mm}$ ) and 59 in group B (mean diameter, $13.17 \pm 1.28 \mathrm{~mm})$. Vein closure rates at 12 months were $98.9 \%$ in group $A$ and $100 \%$ in group $B(P=0.428)$. There was no significant difference in the incidence of complications. Both groups showed marked improvements in the VCSS and the AVSS with no significant differences.

Conclusion: For large-diameter veins, RFA showed comparable outcomes in terms of closure rate, complications, clinical and QoL improvements.

[Ann Surg Treat Res 2019;96(6):313-318]
\end{abstract}

Key Words: Varicose veins, Radiofrequency ablation, Saphenous vein

\section{INTRODUCTION}

Since late 1990s, the treatment for varicose veins has undergone dramatic changes with the introduction of percutaneous endovenous ablation techniques, including endovenous laser treatment, radiofrequency ablation (RFA), foam sclerotherapy and nonthermal nontumescent treatment such as mechanochemical ablation (Clarivein, South Jordan, UT, USA) and Cyanoacrylate glue (VenaSeal, Medtronic, Minneapolis, MN, USA) [1-5]. In randomized controlled trials, endovenous therapy showed better results than high ligation and stripping in terms of pain relief, rapid recovery and improved quality of life (QoL) [6]. Between the 2 thermal endovenous solutions, RFA was associated with less periprocedural pain, requirement for analgesics, and bruising [7].

The RFA technique involves the induction of endofibrosis in the saphenous vein walls by applying heat from the intravenous catheter. RFA of great saphenous veins (GSVs) larger than 12 $\mathrm{mm}$ in diameter has been controversial because of an increased risk of incomplete obliteration and target vein phlebitis [8,9]. After the current second generation ClosureFast (Venefit, Covidien, Mansfield, MA, USA) catheter was introduced in
Received January 21, 2019, Revised March 15, 2019,

Accepted April 1, 2019

\section{Corresponding Author: In Mok Jung}

Department of Surgery, Seoul Metropolitan Government - Seoul National University Boramae Medical Center, 20 Boramae-ro 5-gil, Dongjak-gu, Seoul 07061, Korea

Tel: +82-2-870-2270, Fax: +82-2-870-3861

E-mail: sboy5240@gmail.com

ORCID code: https://orcid.org/0000-0002-5957-4207
*Hye Young Woo and Suh Min Kim contributed equally to this study as co-first authors.

Copyright (c) 2019, the Korean Surgical Society

(c) Annals of Surgical Treatment and Research is an Open Access Journal. All articles are distributed under the terms of the Creative Commons Attribution NonCommercial License (http://creativecommons.org/licenses/by-nc/4.0/) which permits unrestricted non-commercial use, distribution, and reproduction in any medium, provided the original work is properly cited. 
2007, with routine use of tumescent anesthesia, the $12-\mathrm{mm}$ size limitation is no longer considered issue [10-12]. However, there is limited data on both the efficacy and safety of RFA for saphenous veins with a large diameter.

This study aimed to determine whether large-diameter $(>12$ $\mathrm{mm})$ GSV affected closure rate, complications, and clinical and QoL improvement following RFA procedure.

\section{METHODS}

\section{Patients}

This was a retrospective single-center study including patients who underwent RFA due to symptomatic varicose vein with saphenofemoral junction (SFJ) reflux from January 2012 to September 2016. Patients who underwent reoperation and small saphenous vein ablation simultaneously were excluded from the study. Data were collected by medical record review. This study was approved by the Boramae Medical Center Institutional Review Board (approval number: 20-2018-89) with waiver of informed consent because the research would pose no more than minimal risk to the patients and have no adverse effects on the subjects. This study was carried out in accordance with the ethical guidelines of the 1975 Declaration of Helsinki.

\section{Preoperative evaluation}

Clinical severity data were collected using Clinical, Etiology, Anatomy and Pathophysiology (CEAP) classification. Data on symptoms and QoL were collected using the Venous Clinical Severity Score (VCSS) and the Aberdeen Varicose Vein Symptom Severity Score (AVSS) [13,14]. Duplex scan was performed to measure a maximum diameter of GSV. This diameter was recorded $3 \mathrm{~cm}$ below the SFJ in the upright position, according to the International Union of Phlebology consensus document on duplex ultrasound [15]. Thus, patients were divided into 2 groups according to their vein diameter (group A $\leq 12 \mathrm{~mm}$, group B $>12 \mathrm{~mm}$ ).

\section{RFA procedures}

All procedures were performed in an operating room under local anesthesia or monitored anesthesia care. Patients were placed in the supine position and ultrasound-guided puncture of the GSV was done at the level of the knee using a micropuncture needle. Using a flexible guidewire, a 7F sheath was inserted, and the ClosureFast RFA catheter was advanced into the GSV through the sheath. The tip of the catheter was positioned 2.0 to $2.5 \mathrm{~cm}$ distal to the SFJ, and duplex ultrasound was used to confirm the position of the tip of the catheter. Tumescent anesthesia was injected into the tissues surround the GSV with a dose of $10 \mathrm{~mL}$ per $1 \mathrm{~cm}$ length. The heating element was activated with radiofrequency energy to $120^{\circ} \mathrm{C}$ for 20 seconds. Energy was delivered by withdrawing the catheter at an interval of $6.5 \mathrm{~cm}$. After procedures, all patients used a compression stocking for 2 weeks and received nonsteroidal anti-inflammatory drugs (NSAIDs) for a week.

\section{Outcomes}

Follow-up ultrasound evaluation was performed between 3 to 5 days, and at $1,3,6$, and 12 months postoperatively. Complete closure of the saphenous vein was defined as noncompressibility and/or absence of flow signal along the entire treated saphenous vein segment on duplex ultrasound with no discrete segments of patency exceeding $5 \mathrm{~cm}$ from the SFJ [16]. Efficacy was evaluated with the VCSS and the AVSS improvement as well as closure rate. Clinical evaluation was performed 1 month and again at 3, 6, and 12 months following the procedure. Safety was defined based on postoperative complications. Complications after RFA were classified and compared according to guideline from Society of Interventional Radiology Standards of Practice Committee [17]. Endovenous heat induced thrombosis (EHIT) was classified according to the degree of extension of thrombus into the deep venous system [18]. Phlebitis was defined as redness, swelling and pain in the treated area and induration was defined as redness without other inflammatory sign.

\section{Statistical analysis}

Continuous variables are presented as mean \pm standard deviation and were compared with the Student t-test and repeated measures analysis of variance. Chi-square tests were used to compare categorical variables. The Kaplan-Meier method and log-rank tests were used to calculate and compare the closure rates between groups. Statistical significance was determined when the P-value was less than 0.05. Statistical analysis was performed using the IBM SPSS Statistics ver. 19.0 (IBM Co., Armonk, NY, USA).

\section{RESULTS}

\section{Baseline characteristics}

During the study period, 493 consecutive patients with 722 limbs were treated with RFA for incompetent GSV. There were 663 veins in group A with a mean diameter of $6.00 \pm 1.74$ $\mathrm{mm}$ (median, 5.73; range, 3.04-9.88 mm). Group B consisted of 59 veins with a mean GSV diameter of $13.17 \pm 1.28 \mathrm{~mm}$ (median, 12.70; range, $12.10-17.20 \mathrm{~mm}$ ). The mean age was $56.0 \pm 12.7$ years in group A and $56.0 \pm 10.4$ years in group B. No significant differences were observed in follow-up duration $(\mathrm{P}=0.357)$ and percentage of patients with the $\mathrm{C} 2$ in CEAP clinical classification $(81.0 \%$ and $86.4 \%, \mathrm{P}=0.121)$ (Table 1 ). Concomitant ambulatory phlebectomy was performed in 605 patients $(91.3 \%)$ in group A and 59 patients (100\%) in group B. 


\section{Vein closure rate}

Successful closure of the treated GSV was achieved in all patients, and was evaluated with a duplex scan at the end of the procedure. Vein closure rates evaluated with duplex scan in group A were $100 \%, 99.7 \%$, and $98.9 \%$ at 1 month, 6 months, and 12 months, respectively. Vein closure rate in group B was 100\% for each follow-up (Fig. 1). There were no statistically significant differences in vein closure rate at 12 months between the 2 groups $(\mathrm{P}=0.428)$.

\section{Incidence of complications}

Postoperative complications were found in 132 patients (19.9\%) in group A and 8 patients (13.6\%) in group B (Table

Table 1. Demographic characteristics of 722 limbs

\begin{tabular}{lccr}
\hline \multicolumn{1}{c}{ Characteristic } & $\begin{array}{c}\text { Group A } \\
(\mathrm{n}=663)\end{array}$ & $\begin{array}{c}\text { Group B } \\
(\mathrm{n}=59)\end{array}$ & P-value \\
\hline Age $(\mathrm{yr})$ & $56.0 \pm 12.7$ & $56.0 \pm 10.4$ & 0.212 \\
Female sex & $392(59.13)$ & $32(54.24)$ & 0.465 \\
GSV diameter (mm) & $6.00 \pm 1.74$ & $13.17 \pm 1.28$ & $<0.001$ \\
CEAP clinical classification & & & 0.121 \\
C1 & $82(12.4)$ & $0(0)$ & \\
C2 & $537(81.0)$ & $51(86.4)$ & \\
C3 & $19(2.9)$ & $4(6.8)$ & \\
C4 & $23(3.5)$ & $3(5.1)$ & \\
C5 & $1(0.2)$ & $1(1.7)$ & \\
C6 & $1(0.2)$ & $0(0)$ & \\
Follow-up duration (mo) & $8.65 \pm 6.01$ & $9.29 \pm 9.16$ & 0.357
\end{tabular}

Values are presented as mean \pm standard deviation or number (\%).

Group A, vein diameter $\leq 12 \mathrm{~mm}$; group B, vein diameter $>12$ $\mathrm{mm}$; GSV, great saphenous vein; CEAP, Clinical, Etiology, Anatomy, and pathophysiology.

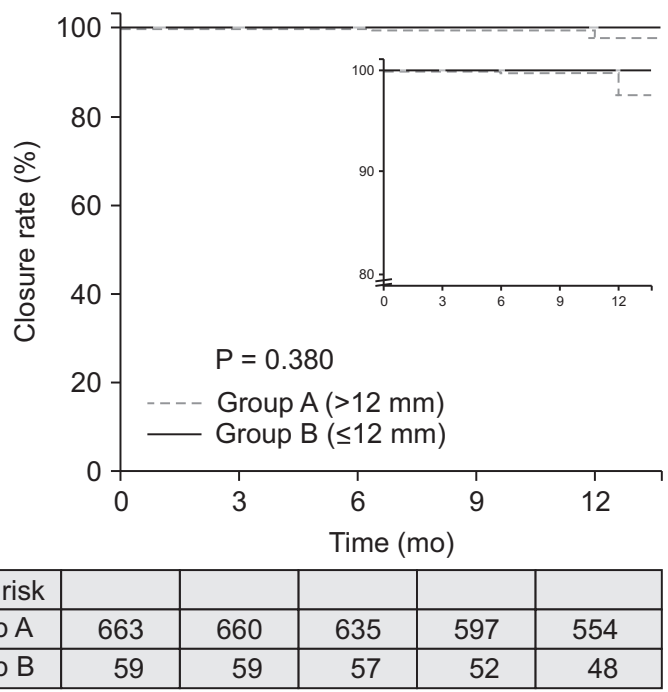

Fig. 1. Vein closure rate after radiofrequency ablation. Group $A$, vein diameter $\leq 12 \mathrm{~mm}$; group $B$, vein diameter $>12 \mathrm{~mm}$.
2). The most common complication was paresthesia, which occurred in 39 cases (5.4\%). Paresthesia disappeared in most cases without additional treatments. There was no statistically significant difference in each complication, including phlebitis and EHIT between the 2 groups. Most patients with phlebitis only required the medications for a few days without the need for hospitalization. No patient in group B experienced severe phlebitis. Two patients (0.3\%) from group A and 1 (1.7\%) from group B experienced EHIT class 3. They received anticoagulation therapy and EHIT resolved completely.

\section{Improvements of VCSS and AVSS}

Mean VCSS improved from $3.52 \pm 1.41$ at baseline to $1.01 \pm$ 0.92 at 1 month and to $0.07 \pm 0.30$ at 12 months in group A. In group B, the mean VCSS score decreased from $3.88 \pm 1.52$ at preoperative survey to $1.07 \pm 0.69$ at 1 month and to $0.06 \pm$ 0.35 at 12 months. Both groups showed marked improvement

Table 2. Incidence of complications

\begin{tabular}{lccc}
\hline \multicolumn{1}{c}{ Complication } & $\begin{array}{c}\text { Group A } \\
(\mathrm{n}=663)\end{array}$ & $\begin{array}{c}\text { Group B } \\
(\mathrm{n}=59)\end{array}$ & P-value \\
\hline Hematoma & $20(3.0)$ & $2(3.4)$ & 0.873 \\
Edema & $11(1.7)$ & $1(1.7)$ & 0.984 \\
Induraiton & $10(1.5)$ & $2(3.4)$ & 0.279 \\
Paresthesia & $38(5.7)$ & $1(1.7)$ & 0.189 \\
Hyperpigmentation & $36(5.4)$ & $0(0)$ & 0.066 \\
Phlebitis & $15(2.3)$ & $1(1.7)$ & 0.605 \\
EHIT & $2(0.3)$ & $1(1.7)$ & 0.111 \\
\hline
\end{tabular}

Values are presented as number of limbs (\%).

Group A, vein diameter $\leq 12 \mathrm{~mm}$; group $\mathrm{B}$, vein diameter $>12$ $\mathrm{mm}$; EHIT, endovenous heat-induced thrombosis.

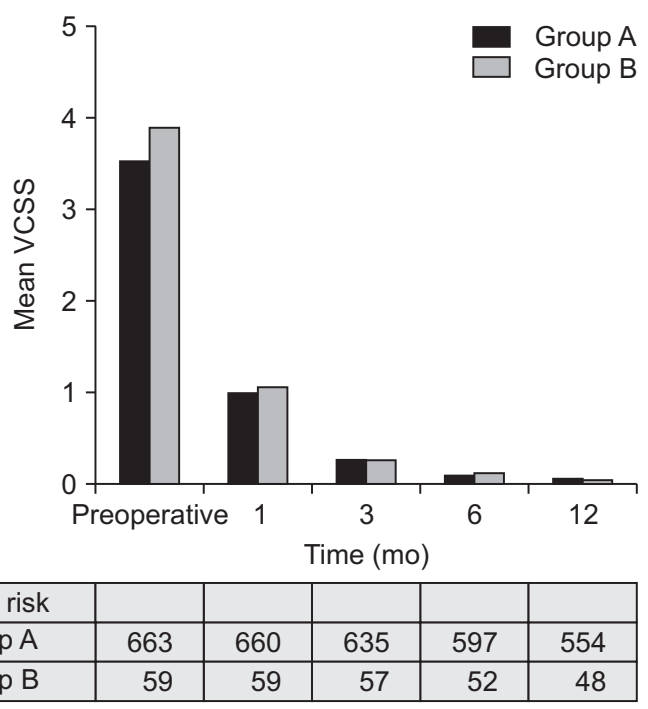

Fig. 2. Changes in the Venous Clinical Severity Score (VCSS). Group A, vein diameter $\leq 12 \mathrm{~mm}$; group B, vein diameter > $12 \mathrm{~mm}$. 


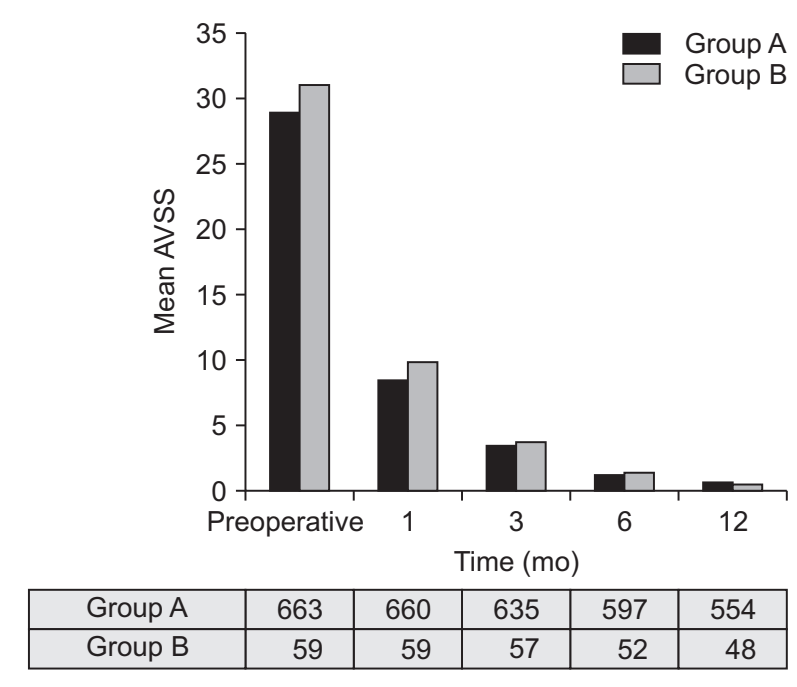

Fig. 3. Changes in the Aberdeen Varicose Vein Symptom Severity Score (AVSS). Group A, vein diameter $\leq 12 \mathrm{~mm}$; group $B$, vein diameter $>12 \mathrm{~mm}$.

of symptoms at $1,3,6$, and 12 months postoperatively, with no significant differences (all P > 0.05) (Fig. 2).

The AVSS, an index of QoL, was measured preoperatively and at $1,3,6$, and 12 months after treatment. Mean AVSS improved from $29.33 \pm 8.07$ at baseline to $8.66 \pm 5.12$ at 1 month and to $0.76 \pm 2.51$ at 12 months in group A. In group B, the mean AVSS decreased from $31.07 \pm 8.54$ at baseline to $9.93 \pm 4.53$ at 1 month and to $0.70 \pm 2.69$ at 12 months. The improvements in the AVSS from the preoperative period to follow-ups at $1,3,6$, and 12 months were not significantly different between the 2 groups (all P > 0.05) (Fig. 3).

\section{DISCUSSION}

The diameter of the saphenous vein was one of the limiting criteria for RFA use previously. The first-generation catheter, ClosurePlus catheter, for RFA consisted of extendable prongs to contact the saphenous vein wall. In the completely deployed state, the larger one, among the available devices, had a dimeter of $12 \mathrm{~mm}$ [10]. Therefore, it was considered that the maximum vein diameter for RFA should be $12 \mathrm{~mm}$ [10]. The secondgeneration RFA-device, ClosureFast catheter, was launched in 2006. With the introduction of this RFA device, its use in GSV larger than $12 \mathrm{~mm}$ is no longer considered a contraindication.

There are several reports on the outcomes of RFA in large diameter GSV. Gloviczki et al. [19] suggested saphenous vein diameters larger than $15 \mathrm{~mm}$ as a limiting factor for RFA because of an increased risk of incomplete obliteration and target vein phlebitis. However, Calcagno et al. [10] firstly evaluated the effect of saphenous vein diameter on closure rate and reported that a saphenous vein diameter larger than $12 \mathrm{~mm}$ had no effect on closure rate with the ClosureFast catheter. In the study by Proebstle et al. [20], even saphenous veins as large as $18 \mathrm{~mm}$ in diameter were treated by RFA with ClosureFast catheter with an overall closure rate of $99.6 \%$.

Our results showed that closure rates exceed $98 \%$ at 12 months regardless of vein diameter. We reported excellent results comparative with those of initial studies with secondgeneration catheters $[20,21]$. Good results were achieved because relatively large number of patients was followed-up and the study was performed after the initial period of second generation of RFA device. Additionally, we showed results with longer-term follow-up than that in the previous study on large diameter veins [10]. We collected the data on the improvements on the VCSS and the AVSS. There were few reports which analyzed these indexes in association with GSV diameter before. We evaluated clinical improvement after RFA using both the VCSS and the AVSS, unlike to a recent study on RFA in large diameter veins [12]. With this, we showed comprehensive results of RFA in larger diameter GSV.

Major complications after RFA ablation were uncommon. The overall major complication rate based on pooled events in RFA cohort studies from Medical Advisory Secretariat evidence review was $2.9 \%$ [22]. Deep vein thrombosis (DVT) is the most frequently mentioned major adverse event. In a study with 2,470 cases with RFA, the incidences of DVT and EHIT were $0.7 \%$ and $0.4 \%$, respectively [23]. In our series, the incidence of EHIT was comparable to the previous report. Moreover, there was no difference between the groups as well. Larger diameter of GSV did not increase the risk of EHIT in our study.

Minor complications, such as paresthesia and hematoma, were relatively common. However, it was not clear to what extent these complications were due to either the primary RFA therapy or concomitant procedures such as phlebectomy. In our cases, ambulatory phlebectomy was performed on most of the cases (664 limbs, 92.0\%). In the previous studies, paresthesia was reported as the most common among the minor complications with an incidence of $3.2 \%$ to $12.3 \%$ [20,24,25]. In our results, the paresthesia was reported $5.7 \%$ and $1.7 \%$ in each group without significant differences. In addition, phlebitis occurred similarly in both groups with low incidence. The vein diameter did not influence the incidence of paresthesia or phlebitis.

Our study had several limitations. First, it was a retrospective study with a relatively short follow-up duration. Data from a longer follow-up duration can provide more conclusive data. Second, all the patients were prescribed NSAIDs. The medication compliance could be different between the groups, which might influence the incidence of phlebitis or pain. Third, as mentioned earlier, concomitantly performed phlebectomy could affect the incidence of complications, such as phlebitis, pain, hyperpigmentation, and paresthesia.

In conclusion, for large-diameter veins, with diameters larger 
than $12 \mathrm{~mm}$, RFA showed comparable outcomes for closure rate, complications, and clinical and QoL improvement. The large diameter of GSV is not a hindrance or contraindication for RFA.

\section{CONFLICTS OF INTEREST}

No potential conflict of interest relevant to this article was reported.

\section{REFERENCES}

1. Proebstle TM, Alm J, Dimitri S, Rasmussen L, Whiteley M, Lawson J, et al. The European multicenter cohort study on cyanoacrylate embolization of refluxing great saphenous veins. J Vasc Surg Venous Lymphat Disord 2015;3:2-7.

2. Hoggan BL, Cameron AL, Maddern GJ. Systematic review of endovenous laser therapy versus surgery for the treatment of saphenous varicose veins. Ann Vasc Surg 2009;23:277-87.

3. Luebke T, Brunkwall J. Systematic review and meta-analysis of endovenous radiofrequency obliteration, endovenous laser therapy, and foam sclerotherapy for primary varicosis. J Cardiovasc Surg (Torino) 2008:49:213-33.

4. Luebke T, Gawenda M, Heckenkamp J, Brunkwall J. Meta-analysis of endovenous radiofrequency obliteration of the great saphenous vein in primary varicosis. J Endovasc Ther 2008;15:213-23.

5. Sun JJ, Chowdhury MM, Sadat U, Hayes PD, Tang TY. Mechanochemical ablation for treatment of truncal venous insufficiency: a review of the current literature. J Vasc Interv Radiol 2017;28:142231.

6. Rasmussen LH, Lawaetz M, Bjoern L, Vennits B, Blemings A, Eklof B. Randomized clinical trial comparing endovenous laser ablation, radiofrequency ablation, foam sclerotherapy and surgical stripping for great saphenous varicose veins. Br J Surg 2011;98:1079-87.

7. Nordon IM, Hinchliffe RJ, Brar R, Moxey P, Black SA, Thompson MM, et al. A prospective double-blind randomized controlled trial of radiofrequency versus laser treatment of the great saphenous vein in patients with varicose veins. Ann
Surg 2011:254:876-81.

8. Lurie F, Creton D, Eklof B, Kabnick LS, Kistner RL, Pichot O, et al. Prospective randomized study of endovenous radiofrequency obliteration (closure procedure) versus ligation and stripping in a selected patient population (EVOLVeS Study). J Vasc Surg 2003:38:207-14.

9. Nicolini P; Closure Group. Treatment of primary varicose veins by endovenous obliteration with the VNUS closure system: results of a prospective multicentre study. Eur J Vasc Endovasc Surg 2005:29:433-9.

10. Calcagno D, Rossi JA, Ha C. Effect of saphenous vein diameter on closure rate with ClosureFAST radiofrequency catheter. Vasc Endovascular Surg 2009;43:56770.

11. Shaidakov EV, Grigorian AG, Iliukhin EA, Bulatov VL, Gal'chenko MI. Analysis of efficacy of radiofrequency obliteration with due regard for the target vein's diameter. Angiol Sosud Khir 2014;20:87-94.

12. Cabrero Fernandez M, Martinez Lopez I, Hernandez Mateo MM, Marques de Marino P, Cernuda Artero I, Serrano Hernando FJ. Prospective study of safety and effectiveness in the use of radiofrequency ablation for incompetent great saphenous vein $\geq 12 \mathrm{~mm}$. J Vasc Surg Venous Lymphat Disord 2017;5:810-6.

13. Rutherford RB, Padberg FT Jr, Comerota AJ, Kistner RL, Meissner MH, Moneta GL. Venous severity scoring: an adjunct to venous outcome assessment. J Vasc Surg 2000;31:1307-12.

14. Garratt AM, Macdonald LM, Ruta DA, Russell IT, Buckingham JK, Krukowski $\mathrm{ZH}$. Towards measurement of outcome for patients with varicose veins. Qual Health Care 1993r;2:5-10.
15. De Maeseneer M, Pichot O, Cavezzi A, Earnshaw J, van Rij A, Lurie F, et al. Duplex ultrasound investigation of the veins of the lower limbs after treatment for varicose veins - UIP consensus document. Eur J Vasc Endovasc Surg 2011;42: 89-102

16. Chan YC, Law Y, Cheung GC, Cheng SW. Predictors of recanalization for incompetent great saphenous veins treated with cyanoacrylate glue. J Vasc Interv Radiol 2017;28:665-71.

17. Sacks D, McClenny TE, Cardella JF, Lewis CA. Society of Interventional Radiology clinical practice guidelines. J Vasc Interv Radiol 2003:14(9 Pt 2):S199-202.

18. Keo HH, Baumann F, Diehm N, Regli C, Staub D. Rivaroxaban versus fondaparinux for thromboprophylaxis after endovenous laser ablation. J Vasc Surg Venous Lymphat Disord 2017:5:817-23.

19. Gloviczki P, Comerota AJ, Dalsing MC, Eklof BG, Gillespie DL, Gloviczki ML, et al. The care of patients with varicose veins and associated chronic venous diseases: clinical practice guidelines of the Society for Vascular Surgery and the American Venous Forum. J Vasc Surg 2011;53(5 Suppl):2S-48S

20. Proebstle TM, Vago B, Alm J, Gockeritz $\mathrm{O}$, Lebard C, Pichot O. Treatment of the incompetent great saphenous vein by endovenous radiofrequency powered segmental thermal ablation: first clinical experience. J Vasc Surg 2008;47:151-6.

21. Creton D, Pichot O, Sessa C, Proebstle TM; ClosureFast Europe Group. Radiofrequency-powered segmental thermal obliteration carried out with the ClosureFast procedure: results at 1 year. Ann Vasc Surg 2010;24:360-6. 
22. Medical Advisory Secretariat. Endovascular radiofrequency ablation for varicose veins: an evidence-based analysis. Ont Health Technol Assess Ser 2011;11:1-93.

23. Marsh P, Price BA, Holdstock J, Harrison C, Whiteley MS. Deep vein thrombosis (DVT) after venous thermoablation techniques: rates of endovenous heat-induced thrombosis (EHIT) and classical DVT after radio- frequency and endovenous laser ablation in a single centre. Eur J Vasc Endovasc Surg 2010;40:521-7.

24. Proebstle TM, Alm J, Gockeritz O, Wenzel C, Noppeney T, Lebard C, et al. Three-year European follow-up of endovenous radiofrequency-powered segmental thermal ablation of the great saphenous vein with or without treatment of calf varicosities. J
Vasc Surg 2011:54:146-52.

25. Merchant RF, Pichot O; Closure Study Group. Long-term outcomes of endovenous radiofrequency obliteration of saphenous reflux as a treatment for superficial venous insufficiency. J Vasc Surg 2005:42:502-9. 